\title{
Os desafios do livro didático como fonte de pesquisa, memória e história em tempos de sociedade da informação
}

Gisela Eggert Steindel

Doutora em Educação. Atua no Programa de PósGraduação em Educação e no Mestrado Profissional em Gestão de Unidades de Informação da Universidade do Estado de Santa Catarina (UDESC)

Daniele Feldman

Bibliotecária graduada pela Universidade do Estado de Santa Catarina (UDESC) Mestranda do Curso de Pós-Graduação em Gestão de Unidades de Informação (PPGinfo/UDESC)

Kayma Kanoon da Silva

Graduanda em Biblioteconomia. Bolsista de Iniciação Científica (PROBIC/UDESC)

http://dx.doi.org/10.1590/1981-5344/2442

O texto é uma reflexão a partir de uma investigação, em andamento, acerca dos acervos didáticos abrigados nas instituições escolares da rede estadual de ensino, circunscritas ao município de Florianópolis, integrante da $18^{a}$ Secretaria Regional do governo de Santa Catarina, cruzados com dados históricos da biblioteca da escola. A investigação é uma pesquisa documental e bibliográfica ancorada nos estudos. Os dados até o momento apontam os primeiros resultados concernentes aos estudos teóricos, o levantamento bibliográfico e da prática de pesquisa demandada.

Palavras-chave: Livro didático; Acervos escolares Fontes de pesquisa; Biblioteca escolar - memória (s); História da Educação e Biblioteca; Sociedade da informação. 


\title{
The book challenges of teaching as a research source, memory and history in times of information society
}

\begin{abstract}
The text is a reflection from an ongoing investigation about the didactic collections housed in the State Schools confined to Florianópolis, member of the 18th Regional Secretary of the Government of Santa Catarina, crossed with historical data from the school's library. The research is documentary and bibliographic research anchored in cultural studies. The data of the investigation indicate the first results concerning the theoretical studies, bibliography literature and the respondent research practice.
\end{abstract}

Keywords: Book text; School Collections - Sources; School Collections; School Library - memory(s); History of Education and Library; Information Society.

Recebido em 22.05.2015 Aceito em 11.03.2016

\section{Contextualização do estudo}

Trata-se de pesquisa iniciada em agosto de 2012. Seu intuito é investigar a temática sobre o acervo didático da biblioteca escolar, na perspectiva de a considerar como fonte de pesquisa e memória(s) num diálogo entre os campos da Biblioteconomia e da Educação. O presente texto objetiva apresentar uma parte dos dados quantitativos obtidos nessa investigação.

A pesquisa se insere num recente movimento internacional, como Portugal, Espanha e França, no campo da Educação, preocupado com a criação, a instalação e a preservação de programas e projetos que organizam acervos de/sobre livros didáticos. A França é provavelmente pioneira nesse tipo de iniciativa, que teve à frente o trabalho do professor e pesquisador Alain Choppin, que criou o Banco de Dados Emmanuelle 1 . Outros programas ainda são dignos de nota, como alguns mais próximos de nós, como, na Argentina, o Projeto Histelea, da Universidad Nacional de Lujá. Já no Brasil, o Projeto Livres, desenvolvido na Faculdade de Educação da Universidade de São Paulo (USP); o Projeto Hades, criado e mantido pela Universidade Federal do Espírito Santo (UFES) e, muito mais longe de nós, no continente africano, o Programa Aequatoria, na República Democrática do Congo (LEITE; PIROLA, 2009).

1 CHOPPIN, A. História dos livros e das edições didáticas: sobre o estado da arte. Disponível em: <http://www.scielo.br/pdf/ep/v30n3/a12v30n3.pdf>. Acesso em: 14 mar. 2016. Destaca-se que o banco de dados Emmanuelle está acessível desde 2001. 
A biblioteca compreende um lugar entre as diferentes formas de expressão da comunicação humana: as técnicas de escrita impressa, digital, iconográfica e na memória, como afirmam Baratin e Jacob (2000, p. 9). Nessa assertiva, é também:

[...] o teatro de uma alquimia complexa em que, sob o efeito da leitura, da escrita e de sua interação, se liberam as forças, os movimentos do pensamento. É um lugar [...] de criação e inovação, e a conservação só tem sentido como fermento dos saberes e motor dos conhecimentos, a serviço da coletividade inteira.

A instituição biblioteca como filha da história nos seus diferentes tempos, pode-se assumir a biblioteca pública, como hoje a entendemos, é herança dos tempos modernos - e neste texto aqui entende-se que a biblioteca escolar no Brasil como resultado do esforço de um processo de civilização realizado pela instituição escolar da sociedade brasileira ancorada em um sistema de educação possível de se observar nos estudos e registros da história da educação brasileira (VEIGA, 2003; MACHADO, 2002) -, a biblioteca da escola passa a ser compreendida como item de interesse das políticas educacionais a partir do Manifesto dos Pioneiros da Educação Nova (1932). Passados mais de 60 anos, a Unesco num horizonte mundial, adota como um dos itens das suas políticas, inspirada no Manifesto da Biblioteca Pública do século XX, publica o Manifesto à Biblioteca Escolar, mais precisamente em 1999 nos termos do ensino-aprendizagem para todos, a seguinte declaração:

A biblioteca escolar proporciona informação e ideias fundamentais para sermos bem sucedidos na sociedade atual, baseada na informação e no conhecimento. A biblioteca escolar desenvolve nos estudantes competências para a aprendizagem ao longo da vida e desenvolve a imaginação, permitindo-lhes tornarem-se cidadãos responsáveis (FEDERAÇÃO INTERNACIONAL DE ASSOCIAÇÕES DE BIBLIOTECÁRIOS E BIBLIOTECAS - IFLA, 2006, p. 4).

Além das políticas educacionais, a biblioteca escolar contemporânea, interesse específico da presente proposta investigativa, tem sido objeto de estudos, especialmente na Biblioteconomia e História, e, a partir dos anos 90 do século $\mathrm{XX}$, pelos estudos culturais circunscritos à História da Educação, estes com interesse no estudo do impresso em diferentes instituições.

No campo da Biblioteconomia, podemos afirmar que a biblioteca escolar passa a dar maior ênfase ao arco de tempo que compreende fins da década de 80 e, mais particularmente, dos anos 90 do século XX, centrando-se na bibliografia nacional, preocupada em assinalar a inexistência da biblioteca escolar no sistema educacional brasileiro. Citamos o trabalho de Silva (1995), que entende que a palavra que melhor define a biblioteca escolar no Brasil é "silêncio". Outros autores, 
como Milanesi (2003), Fragoso (2002) e Campello e Vianna (2003), observam essa biblioteca como um centro de informação múltiplo, necessário ao diálogo com a comunidade escolar.

No excerto abaixo Silva (1999 citado por LEITE; PIROLA, 2009, p. 89), aponta outra importante questão, isto é, o distanciamento entre duas importantes áreas de estudo que focam propósitos de atuação na biblioteca escolar e no processo ensino-aprendizagem, a dicotomia explícita entre Pedagogia e Biblioteconomia, com uma afirmativa contundente:

A biblioteca escolar parece desconhecida por ambos os campos que, teoricamente, transferiram sua suposta responsabilidade pelo desenvolvimento da mesma, para que o outro segmento a adotasse, não reconhecendo sua própria responsabilidade. Ou, veladamente, impuseram suas estruturas para que a biblioteca escolar as incorporasse indistintamente. Esta espécie de conflito juntamente com o descaso de autoridades governamentais relegou a biblioteca escolar a uma colocação bem peculiar. Nesse sentido, em alguns momentos a rigidez da Biblioteconomia e dos métodos educacionais infligiu à biblioteca escolar padrões igualmente rígidos, transformando-a em um espaço frio, burocratizado e estático dentro da instituição da qual fazia parte - sua escola.

De algum modo, a reflexão desses autores faz pensar nos acervos das bibliotecas escolares, pois é correto afirmar que a escola e a biblioteca têm um diálogo em comum - a informação e 0 conhecimento -, independente de sua forma (escolar, cultural, social e/ou política).

A informação e o conhecimento constituem o insumo básico da sociedade da informação. Para o sociólogo catalão Manuel Castells:

[...] a revolução tecnológica deu origem ao informacionalismo, tornando-se assim a base material desta nova sociedade [sociedade da informação], em que os valores da liberdade individual e da comunicação aberta tornaram-se supremos. Segundo o autor, no informacionalismo, as tecnologias assumem um papel de destaque em todos os segmentos sociais, permitindo o entendimento da nova estrutura social sociedade em rede - e, consequentemente, de uma nova economia, na qual a tecnologia da informação é considerada uma ferramenta indispensável na manipulação da informação e construção do conhecimento pelos indivíduos, pois a geração, processamento e transmissão de informação torna-se a principal fonte de produtividade e poder (CASTELLS, 1999, p. 21 citado por COUTINHO; LISBOA, 2011 , p. 7, grifos do autor).

A citação permite afirmar que o autor, e os que o citam, entendem que escola e biblioteca são partícipes da sociedade da informação em construção. As reflexões aqui esboçadas apontam para a necessidade de 
se construir e fortalecer o dialogo entre os campos da Educação e da Biblioteconomia na sociedade de informação. Para tanto, coloca-se como foco deste estudo a seguinte questão:

Os acervos didáticos existentes nas bibliotecas das escolas estaduais localizadas no município de Florianópolis revelam de algum modo indícios e possibilidades de fonte de pesquisa e memória(s) para o campo da biblioteconomia e da educação?

O objetivo geral é mapear os acervos didáticos abrigados nas instituições escolares da rede estadual de ensino, circunscrita ao município de Florianópolis, integrante da $18^{\circ}$ Secretaria Regional do governo de Santa Catarina.

Já os específicos, interpretativos do objetivo geral proposto, assim se apresentam:

a)identificar a produção técnico-científica empreendida no campo da biblioteconomia brasileira no século XXI e, nessa mesma linha, verificar que estudos do campo da educação dialogam com a biblioteconomia nesse mesmo período;

b)identificar e arrolar os acervos existentes nas bibliotecas escolares da rede estadual de ensino público situadas no município de Florianópolis;

c)registrar práticas empíricas entre as diretrizes de formação e desenvolvimento de coleções adotadas nessas bibliotecas;

d)determinar qual a idade desses acervos, no contexto da literatura do campo da Biblioteconomia;

e)compreender em que medida os acervos existentes podem constituir fonte de pesquisa e memória(s) nesses campos; por fim,

f)apreender uma noção de representação a partir dos livros didáticos que compõem uma parte do acervo da biblioteca escolar investigada.

\section{Metodologia de trabalho}

Esta proposta utiliza diferentes metodologias, procedimentos e fontes capazes de alcançar o objetivo da investigação. Assim, vêm-se empreendendo o estudo descritivo dos acervos e o estudo de uma noção de representações do acervo didático existente nas instituições escolares definidas para este estudo.

Paralelamente, está em andamento uma pesquisa bibliográfica quanti-qualitativa da produção científica relativa ao livro/acervo didático nas áreas de Biblioteconomia e Educação. O estudo da produção bibliográfica tem como alvo as áreas das Ciências Sociais Aplicadas I Biblioteconomia e Ciência da Informação e Educação -, assumidas como pauta para a composição da amostra da pesquisa bibliográfica, de acordo com os seguintes cortes para o levantamento bibliográfico. Artigos de revistas da área de avaliação/CAPES: Ciências sociais Aplicadas I e Educação. Qualis A - 1, A - 2, B - 1 e B - 2. Idioma - português, espanhol e inglês. Termos de busca: educação, história da educação, ciência da educação, educar, biblioteca, biblioteconomia, ciência da 
informação, informação, dados, leitura. Período de levantamento (2000 2014).

Seguindo uma terceira estratégia, pretende-se capturar representações dos acervos didáticos existentes nas bibliotecas das instituições escolares delineadas para este estudo, isto é, produzir arquivos de imagens fotográficas dos acervos didáticos existentes na biblioteca escolar. Na trilha de Pesavento (2008, p. 14), tomamos como noção de representação "[...] a presentificação de uma ausência, em que representante e representado guardam entre si relações de aproximação e distanciamento".

Calcados nos aportes teórico-metodológicos balizados na literatura nos campos da Educação e da Biblioteconomia, apresentamos, no item que se segue, os apontamentos e as reflexões iniciais até o momento efetuados.

\section{Dados, impressões e reflexões}

\subsection{Coleta de dados nas unidades escolares}

O levantamento dos dados quantitativos dos acervos de livros didáticos foi efetuado em duas unidades escolares: um, na Ilha de Santa Catarina, a Escola Básica Estadual Leonor de Barros, situada no Bairro do Itacurubi. Esta instituição oferece ensino fundamental (do $1^{0}$ ao 90 ano) e ensino médio (do $1^{\circ}$ ao $3^{\circ}$ ano, período diurno e noturno) e possui uma biblioteca com um acervo de mais de 7 mil títulos e recebe doações da comunidade do Itacorubi.

No conceito de livro didático, ainda de acordo com a concepção de Junior Gatti (2004), compreendem-se títulos publicados a partir da década 70 do século XX. Neste sentido, identificaram-se e se registraram cerca de 294 títulos. Observa-se, neles múltipla autoria - de equipe - ou, como aparece em alguns títulos, "autoria colaborativa. Ver a Tabela 1.

Tabela 1 - Mapeamento do Acervo de Livros Didáticos - Escola Básica Estadual Leonor de Barros

\begin{tabular}{l|c}
\hline \multicolumn{1}{c|}{ Área de conhecimento do Livro Didático } & Total de títulos na Unidade Escolar (n=294) \\
\hline \hline Ciências/Biologia & 31 \\
\hline Cultura Africana & 03 \\
\hline Dicionários & 14 \\
\hline Filosofia & 06 \\
\hline Física & 23 \\
\hline Geografia & 44 \\
\hline História & 60 \\
\hline Inglês & 16 \\
\hline Literatura Infanto-Juvenil & 13 \\
\hline Matemática & 45 \\
\hline Português & 23 \\
\hline Poesia/Poema/Lenda & 06 \\
\hline Química & 07 \\
\hline Sociologia & 03 \\
\hline Total & $\mathbf{2 9 4}$ \\
\hline
\end{tabular}

Fonte: Dados da pesquisa. 
Já, em contrapartida, o levantamento possibilitou identificar nesse acervo 13 publicações que, de acordo com a definição de Junior Gatti (2004), se podem chamar de manuais escolares. Esses manuais têm como conteúdo estudos sobre história (universal, geral e de Santa Catarina), língua e literatura portuguesa, matemática, além de uma abordagem sobre história da droga. Este último tema é tratado sob a denominação socialmente compreendida de tóxicos entre jovens. A autoria, no geral, é única ou pode compreender até dois autores.

Quanto aos dados sobre copyright, observa-se que o livro mais antigo data de 1941. Há indícios que nos permitem supor que esse título circula no Brasil há mais de 50 anos. O manual com copyright mais recente é do ano de 1961. A especificidade de qualificação e filiação institucional - qualificadores de autoria - é apresentada em apenas dois títulos: CUVILLIER, A. Manual de filosofia (1948), em versão do professor dr. Vieira de Almeida, da Faculdade de Letras de Lisboa" e PINHEIRO, Virgílio A. Noções de geometria descritiva I: ponto - reta - plano. 5. ed. (1961) - "Professor do magistério do exército e da UFRJ ". Ver Tabela 2.

Tabela 2 - Mapeamento do Acervo de Manuais Didáticos - Escola Básica Estadual Leonor de Barros

\begin{tabular}{l|c}
\hline \multicolumn{1}{c|}{ Área de conhecimento do manual } & $\begin{array}{c}\text { Total de títulos na Unidade Escolar } \\
(\mathbf{n = 2 9 4})\end{array}$ \\
\hline \hline Filosofia & 02 \\
\hline Geografia & 02 \\
\hline História & 07 \\
\hline Literatura & 01 \\
\hline Matemática & 01 \\
\hline TOTAL & $\mathbf{1 3}$ \\
\hline
\end{tabular}

Fonte: Dados da pesquisa.

A segunda instituição escolar na qual foram coletados dados acerca do acervo de livros didáticos existentes na biblioteca foi a Escola Estadual Básica Rosinha Campos.

Essa instituição se situa na região continental da Grande Florianópolis. Compreende o ensino de educação fundamental (do $1^{\circ}$ ao 90 ano, períodos matutino e vespertino). Tem aproximadamente 205 alunos e 19 professores; destes, dez são professores efetivos e nove, professores não efetivos.

No que tange ao funcionamento, a biblioteca é aberta à comunidade escolar, mas somente às terças-feiras; para tanto, porém, conta somente com uma pessoa para sua gestão. $\mathrm{Na}$ Tabela 3, apresenta-se $\mathrm{o}$ quantitativo do acervo mapeado. 
Tabela 3 - Mapeamento do Acervo de Livros Didáticos - Escola Básica Estadual Rosinha Campos

\begin{tabular}{l|c}
\hline $\begin{array}{c}\text { Área de conhecimento do Livro } \\
\text { Didático }\end{array}$ & $\begin{array}{c}\text { Total de títulos na Unidade Escolar } \\
(\mathbf{n = 2 5 8})\end{array}$ \\
\hline \hline Ciências/Biologia & 51 \\
\hline Geografia & 58 \\
\hline História & 60 \\
\hline Letramento e Alfabetização & 07 \\
\hline Matemática & 58 \\
\hline Química & 2 \\
\hline Química e Física & 1 \\
\hline Português & 21 \\
\hline Total & $\mathbf{2 5 8}$ \\
\hline
\end{tabular}

Fonte: Dados da pesquisa.

No sentido de uma leitura quantitativa, observou-se que $50 \%$ dos títulos se destinam ao grupo de alunos do $1^{\circ}$ ao $5^{\circ}$ ano; os outros $50 \%$ dos títulos disponíveis estão voltados ao grupo de alunos do $6^{\circ}$ ao $9^{\circ}$ ano escolar. Está prevista ainda outra etapa para a análise de variáveis como: autoria, qualificação profissional e vínculo institucional, entre outras.

No item que se segue, serão apresentados dados da pesquisa bibliográfica referentes a uma das metodologias adotadas.

\subsection{Primeiros resultados do levantamento bibliográfico em periódicos científicos, na área de Ciências Sociais e Aplicadas em Educação}

A pesquisa bibliográfica propõe-se levantar itens bibliográficos disponíveis nos mais diferentes tipos de produção científica nos seus diversos formatos. Trata-se de uma pesquisa com fontes impressas, ou digitais, para as quais se estabelece um foco, representado por uma ou mais questões de investigação. No bojo desta pesquisa bibliográfica, a identificação e a análise dos artigos científicos se pautam nas seguintes questões:

a)quais os conceitos formulados sobre o livro didático no campo da Biblioteconomia e da Educação?

b)quais os estudos sobre o livro didático empreendidos no campo da Biblioteconomia brasileira no século XXI?

c) que estudos sobre o livro didático do campo da Educação dialogam com a Biblioteconomia no período delimitado para o presente estudo?

Os termos utilizados neste primeiro levantamento são: livro didático; acervo didático; biblioteca escolar; escola; libro de texto; libro didáctico; colección didáctica; escuela; biblioteca de la escuela; book didactic; collection didactic; school library e school.

O empreendimento identificou um total de 48 títulos de periódicos (área das Ciências Sociais Aplicadas I, com 22 títulos; já a área de 
Educação, 26 títulos). Do conjunto de 48 títulos, foram identificados 20 artigos.

A Tabela 4 mostra a distribuição dos artigos na área de Ciências Sociais Aplicadas I.

Tabela 4 - A Publicação de artigos na área de Ciências Sociais e Aplicadas I

\begin{tabular}{|c|c|c|}
\hline Titulo do Período & Qualis & Publicação n음 \\
\hline Dados, Rio de Janeiro (impresso) & \multirow{8}{*}{ A1 } & 0 \\
\hline El profissional de la información & & 0 \\
\hline Information Research & & 0 \\
\hline Informação \& Sociedade (impresso e online) & & 0 \\
\hline Investigação Bibliotecológica & & 0 \\
\hline Library Trends & & 0 \\
\hline Perspectivas em Ciências da Informação & & 0 \\
\hline Transinformação & & 0 \\
\hline Educação e Sociedade & \multirow{5}{*}{$\mathrm{A} 2$} & 3 \\
\hline Education for Information & & 0 \\
\hline New Library World & & 0 \\
\hline Revista Interamerica de Bibliotecología & & 0 \\
\hline The International Information \& Library Review (print) & & 0 \\
\hline Biblios Lima & \multirow{5}{*}{ B1 } & 0 \\
\hline Ciência da Informação (impresso e online) & & 0 \\
\hline Ciencias de la Informacion (impressa) & & 0 \\
\hline Datagramazero, Rio de janeiro & & 0 \\
\hline Educar em Revista (impresso) & & 0 \\
\hline Art Libraries Journal & \multirow{5}{*}{ B2 } & 0 \\
\hline $\begin{array}{l}\text { BID. Textos Universitarios de } \\
\text { Documentatión }\end{array}$ & & 0 \\
\hline Comunicação e Educação & & 0 \\
\hline Educação e Realidade & & 2 \\
\hline TOTAL: 22 títulos & & \\
\hline
\end{tabular}

Fonte: Dados da pesquisa.

No que tange a indicadores Qualis Capes, há uma predominância entre o Qualis A2 e B2 na área da Ciências Sociais Aplicadas I. Quantitativamente, as publicações desses artigos assim se distribuem ao longo do tempo:

a) 2000, dois artigos nas revistas Qualis A2;

b) 2011, artigo publicado no periódico Qualis A2; e

c) 2012, dois na revista Qualis B2.

Observa-se um comportamento de publicação em pontos extremos: 2000 e 2012.

Uma primeira análise já mostra mais equilíbrio dessa variável na área da Educação, como se pode observar na Tabela 5. 
Tabela 5 - Publicação de artigos na Área de Educação

\begin{tabular}{|c|c|c|}
\hline Titulo do Período & Qualis & Publicação no \\
\hline Educação e Pesquisa (USP impresso) & \multirow{6}{*}{ A1 } & 3 \\
\hline Educação em Revista (UFMG impresso) & & 1 \\
\hline Research in Science Education & & 0 \\
\hline Revista Brasileira de Educação & & 1 \\
\hline Revista Brasileira de História da Educação & & 0 \\
\hline Revista Lusófona de Educação & & 0 \\
\hline Cadernos de História da Educacão & \multirow{11}{*}{ A2 } & 1 \\
\hline Cadernos de Educação (UFPel) & & 0 \\
\hline Cultural Studies of Science Education (print) & & 0 \\
\hline Educação (PURS impresso) & & 0 \\
\hline Education Review (London) & & 0 \\
\hline História da Educação (UFPel) & & 2 \\
\hline Revista Brasileira de Política e Administração da Educação & & 0 \\
\hline Revista de Educação Pública & & 0 \\
\hline Revista Educação em Questão (online e impresso - UFRN) & & 2 \\
\hline Revista Portuguesa de Educação & & 0 \\
\hline The Review of Education/Pedagogy/cultural Studies & & 0 \\
\hline Educação (UFSM) & \multirow{13}{*}{ B2 } & 0 \\
\hline Educação Unisinos & & 0 \\
\hline Educação, Sociedade e Culturas & & 0 \\
\hline Educação em Foco (Belo Horizonte) & & 0 \\
\hline Educação em Foco (Juiz de Fora, MG) & & 4 \\
\hline História de La Education & & 0 \\
\hline Revista Brasileira de Estudos Pedagógicos (impresso) & & 0 \\
\hline Revista Iberoamericana de Educación (impresso e online) & & 1 \\
\hline Educação (Rio Claro, SP) & & 0 \\
\hline Educativa (Goiânia, online) & & 0 \\
\hline Perspectives Documentairesen Education & & 0 \\
\hline Teoria e Prática da Educação & & 0 \\
\hline TOTAL: 29 títulos & & \\
\hline
\end{tabular}

Fonte: Dados da pesquisa.

Em comparação com os dados da Área de Ciências Sociais Aplicadas I, os indicadores Qualis Capes, há uma predominância entre o Qualis A1, 0 A2 e o B2 na Área da Educação. A distribuição obedece aos dados mostrados a seguir:

Publicações na revista Qualis A1:
a)2004: dois artigos;
b) 2006; um artigo;
c) 2013, dois artigos.

Publicações nos periódicos Qualis A2:

a)2004: um artigo;

b)2008/2011: um artigo a cada ano. 
Publicações na revista Qualis B2:

a)2003 e 2004: três artigos;

b) 2005: um artigo;

c) 2008: um artigo.

O estudo bibliográfico, em termos quantitativos, no que tange à publicação de artigos com foco no livro didático, permite inferir que ao período considerado é tímida a publicação. Neste sentido, o delineamento da pesquisa deverá sofrer modificações, na tentativa de melhor mapear a produção científica nos campos do conhecimento eleitos para a presente investigação.

\section{Considerações provisórias}

A investigação, que tem como foco o livro didático como fonte de pesquisa, história e memória(s), tanto para o campo da Biblioteconomia, como para o da Educação, há vários pontos, em termos quantitativos, a se destacar nos tempos da sociedade de informação.

- O mapeamento dos acervos didáticos tem-se mostrado um trabalho detalhista e pouco profissional. Dito de outro modo, as bibliotecas escolares da rede pública estadual de Santa Catarina não possuem qualquer tipo de catálogo ou registro dos títulos existentes em suas bibliotecas. O levantamento vem sendo realizado título a título, o que diminui a possibilidade de mapear os acervos de todas as 36 unidades escolares inicialmente propostas. A ambição do pesquisador sucumbe diante do quantitativo versus tempo e energia demandados para tal.

- No entanto, esse ir e vir entre as unidades escolares, tem oportunizado aos proponentes da pesquisa uma imersão no ambiente escolar e, deste modo, construir sensibilidades relativamente às questões das escolas e suas pseudo bibliotecas escolares, ao se observar que, apesar de acervos com qualidade financiados pelo Programa Nacional do Livro didático (PNLD), são relegados ao silêncio, uma vez que não recebem a devida organização e gestão, nem lhes é facultado o acesso (SILVA, 1995).

- O investimento nas leituras no campo da Educação, cruzado com os estudos no campo da Biblioteconomia, levam a suspeitar que o livro didático constitui uma das variáveis às poucas políticas de incremento às bibliotecas escolares brasileiras. O indício se pauta no estudo de Ear e Kornics (2005). O estudo foi uma solicitação do Banco Nacional do Desenvolvimento (BNDES). Os autores constataram, entre as muitas variáveis que dizem respeito à economia da informação, que o Brasil ocupa uma terceira posição em nível mundial na compra de livros para a educação (isto é, livros para doação a estudantes); no entanto, é o único país que não compra livros para as bibliotecas, notadamente para as públicas e escolares. Dito de outro modo, não há uma política de acesso à 
informação no conceito de gestão (planejamento, avaliação). O gargalo do acesso ao livro como bem cultural/educacional reflete posições políticas e econômicas.

- A reflexão acima se confirma com a de Gatti Junior (2004, p. 17), ao mostrar o mecanismo do uso livro didático com as seguintes palavras:

[...] a necessidade de abrigar grandes contingentes populacionais sem investimentos do Estado, acarretou uma situação trágica em que ausência de professores qualificados [...] o livro didático apareceu como caminho que poderia assegurar a qualidade da educação recebida por todos que estivessem na escola.

Finalizando, no que se refere ao estudo bibliográfico, infere-se que para a amostra de títulos de periódicos e o corte temporal (2000-2014), a identificação de 20 artigos é pouco relevante, não alcançando uma média de dois artigos por ano. A escolha do indicador Revista Qualis A-1, A-2, B-1 e B-2 - área de avaliação/CAPES: Ciências sociais Aplicadas I e Educação - pode ter contribuído para o resultado. Na qualidade de proponentes, observamos que será necessário ampliar os descritores ou palavras-chave nos idiomas para uma melhor captura de artigos.

Além dos objetivos estabelecidos para a presente investigação, o estudo mostra ser necessário estabelecer estratégias de sensibilização junto à comunidade escolar no sentido de valorizar o livro didático como fonte de pesquisa, memória e história da sociedade de informação.

\section{Referências}

BARATIN, M.; JACOB, C. (Dir.). O poder das bibliotecas: a memória dos livros no Ocidente. Rio de Janeiro: Editora UFRJ, 2000.

CAMPELLO, B. S.; VIANNA, M. M. A biblioteca escolar: temas para uma prática pedagógica. 2. ed. Belo Horizonte: Autêntica, 2003.

CASTELLS, M. A era da informação: economia, sociedade e cultura. São Paulo: Paz e terra, 1999. v. 3.

CHOPPIN, A. História dos livros e das edições didáticas: sobre o estado da arte. Educação e Pesquisa, São Paulo, v. 30, n. 3, p. 549-566, set./dez. 2004.

COUTINHO, C.; LISBOA, E. Sociedade da informação, conhecimento e da aprendizagem, para educação no século XXI. R. Educ., Lisboa, v. 28, n. 1, p. 5-22, 2011.

EAR, F. S.; KORNIS, G. A economia da cadeia produtiva do livro. Rio de Janeiro: BNDES, 2005.

FRAGOSO, G. M. Biblioteca na escola. Rev. ACB: Biblioteconomia em Santa Catarina, Florianópolis, v. 7, n. 1, 2002. 
FEDERAÇÃO INTERNACIONAL DE ASSOCIAÇÕES DE BIBLIOTECÁRIOS E BIBLIOTECAS (IFLA). Manifesto da biblioteca escolar da IFLA/UNESCO. Vila Franca de Xira (Portugal): [S. n], 2006.

GATTI JÚNIOR, D. A escrita escolar da história: livro didático e ensino no Brasil (1970-1990). Bauru: EDUSC; Uberlândia: Ed. da UFU, 2004.

LEITE, J. L.; PIROLA, A. L. B. Acervos e fontes para a História da Educação: possibilidades de bibliotecas escolares e livros didáticos. Documento Monumento, Cuiabá (MT).Revista Eletrônica do NDIHR/ UFMT, v. 1 , n. 1, p. 87-96, dez. 2009. Disponível em: <http://www.livroehistoriaeditorial.pro.br/ii_pdf/Jucara_L_Leite.pdf>. Acesso em: 14 mar. 2016.

MACHADO, A. A implantação de bibliotecas escolares na rede de ensino de Santa Catarina (décadas de 30 e 40). 2002. 132f. Dissertação (Mestrado em Educação e Cultura) - Centro de Ciências da Educação, Universidade do Estado de Santa Catarina. Florianópolis, 2002.

MILANESI, L. A casa da invenção: biblioteca centro de cultura. 4. ed. rev. ampl. Cotia: Ateliê, 2003.

PESAVENTO, S. J. História, história cultural. Belo Horizonte: Autêntica, 2008.

SILVA, W. C. da. A miséria da biblioteca escolar. São Paulo: Cortez, 1995.

VEIGA, C. G.; LIMA, T. de (Org.). História e historiografia da educação no Brasil. Belo Horizonte: Autêntica, 2003. 